This report was prepared as an account of werk sponsored by the United States Government. Neither the United States nor the United Stutes Atomic Energy Commission, nor any of their employees, nor any of their contractors, subcontrectors, or their employees, makes any warranty, express or im. plied, or asumes any legal liability or responsibility for the sccuracy. com. pleteness or usefulness of any information, apparatus, product or process disclosed, or represents that its use would not infringe privately owned rights.

In the interest of prompt distribution, this LAMS re. port was not edited by the Technical Information saff.

Printed in the United States of America. Available from National Technical Information Service

U. S. Department of Commerce

5285 Port Royal Road

Springfield, Virginia 22151

Price: Printed Copy S4.00; Nlicrofiche $\$ 1.45$ 


\title{
A Method for Increased Accuracy in Eulerian Fluid Dynamics Calculations
}

by

\author{
W. C. Rivard \\ O. A. Farmer \\ T. D. Butler \\ P. J. O'Rourke
}

This work partially supported by the US Air Force under Project Orders AFWL 72.067 and 73.103.

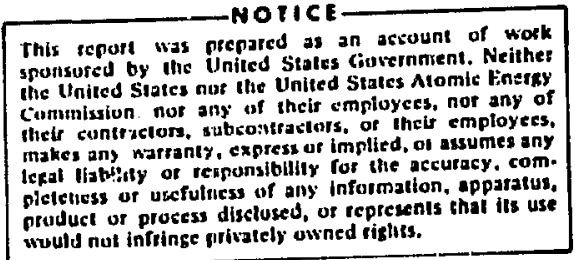




\section{CONTENTS}

Page

Abserace

1

I. Ineroduct Ion

11. Theory of the Truncation Error Cancellation (TEC) Method -

III. Application of the TEC Hethod -

A. Diffustonal Truncation Errors for the RICE Equatione -

B. Stabilization of the RiCg Rquatione 7

IV. DLffuelonal bete

v. Huserdcal Examples _

v1. Sumery

Appendix A. Decivation of tir: TEC Method

Appendix B. Truncation Errors for the RICE flov Equatione 
A METHOD FOR INCREASED ACCURACY

IN EULERLAN FUUID DYMAICS CALCULATIONS

by

\author{
W. C. RIvard \\ T. D. Butler \\ O. A. Parwer
}

P. J. D'Rourike

\begin{abstract}
A mechod for Increaced accuracy in Eulerilan fluld dynanics calculations in described. The estence of the wethod lo local cancellacion of lov-order, diffusional cruncation errors. These errors are the source of notlinear numerlcal instablilties. The nethodology is degcribed in general and specific appllcation io made to the r:auslent, cwo-diaenslonal fiou equations for cheatcally reacting atxeures. Tro exeple problews are solved to illuserate the sethod. For comparison, the same probless are solved with an artificlal viecosity technique.
\end{abstract}

\section{IRTRODJCTION}

Cowputer calculacions of elme-dependent fluld flows often require the solution of finite difference equations that are inherently unstable. An unstable solution ogcillaces or grows unbounded in trae and In no way reseables the physical flow. Considerable attention has been given to understanding and conerolling these Instabllities. The rourter analyals of Von Meumann is successful for anolyzins linear zquations. Thls mechod, however, ylelds only 11-ited Inforation when appled to the nonlincar equations of fluld dyanal:so. The nonlinear scabilicy propertles have becn successfully inveselgeted by Hire.? Hite examines the low order truncarion errors that lead to diffusion of the dependent varlable, e.s.. fensity in the contiaulty cquation. He concludes thut the solution w11l be unatable (1.c., exponenelaliy groulng in tiwe) when the algebrale alen of the diffusion coefficient is nesot 1 ve.

It is wall known that the inclusion of an artieiclal viscosiey in the wosentur equation is an effective weane of waintaining the scabilicy of that equetion. A properly chosen anoubt of srifical viscosity can comter any negutive diffurion ardains fron the cruncselon errors. One wuse be excresely carefui, however, In the use of artificial viscosity for calculactons in wore than one space dimension. For exrmple if the same coeffictent is used, say to diffuse pu-monentu in the $x$ and $y$ directions, excessive diffusion can resule in one direceton. This will occut when the diffusional truncation errors yleld vatiy different diffusion coefficients in tho wo directions, a sicuation thre 1s quite common. It occurs in flous where the nozion is largely directed in a single coordinate direction, since the truncation error diffusion coofficlent in the $x$-direction depends upon the $x$ component of veloclty, $u$, and $3 u / \partial x$, whereas the coefficlent in the y-direction depends upon the $y$ component of velocity, $v_{t}$ and $\partial v / \partial y$.

The purpose of this paper is to describe and iluserace a gencral wethod to stabzlize the findto 
difference equations of Eulerian fluid dynamics by locally computing and canceling the diffuston-1ike cruncation errors. Lagranglan equations are essentially free of these errors since they arise from the convective acceleration terms, but have other problems of their own when distortions are large.

A significant increase in accuracy is achleved with the Truncation Error Cancellation (TEC) wethod over usual artifictal viscosity schemes because exceasive artificial diffusion is eliminated. ihe order of the fintte difference equatiors generally reralns unchanged since all the low order errors, other than those of diffusion, are still present. In this study, no attempt has been made to ellorinate the low order dispersion-like errors arising from the difference equations. Such errors can significantly detract from the accuracy of a given flow calculation. This aspect is discussed in Section II, which presencs the essential 1deas of the TEC method.

The wethod is particularly powerful for the computation of flows with transverse shears, e.g." in boundary layers and mixing layers, and flows where large Reynolds number effects are important. The computational reaults demonstrate a greatiy increased sensitivity to the Reynolds number in conparibon to ordinary artificial viscosticy techniques. As presented herein, the method is approprlate for calculating shock flows providing the shocks are suffictently weak. For strong shocks, the addition of an astefictal viscosity applied in the zegion of the shock 18 necessary to provide the required kinetic energy diseipation.

ro Indicate the relative ease of applying this wethod in complex fluid dynamics codes and to 11lustate 1ts effectiveness, a specific application 18 made to the RICE ${ }^{3}$ code. This code is used to Bolve transient, two-dimensional, compressible flow wth opecies w1xing and chemical reactions. Detallo of the application are presented in Section III. RICE uses the ICE ${ }^{4}$ aolution technique, an impliclt Eulerian schese for flows at arbitrary sach number. The difference equations are fully stabllized with the TEC method by locally cosputing and cancelling the low order diffusional truncation exrors. The atabilicy theory of H1rt is used to feteralne the truncation errora and the form of the diffusion coefficients.
By eliminating excessive diffusion, this method usually allows a significant increase in the computational time step. This is particularly true for high Mach number ( $>$ ) flows when the time step in a typical artificial viscosity scheme is dictated by the diffusional limit obtained from Fourier analysis. In this case a reduction in diffuston results directly In an Increase in time step. Section IV discusses this aspect.

Finally, solution of example problems are presented and compared in Section $v$. The solutions are obtafned first using the TEC method and then using an artificlal viscosity treatment. The increased accuracy of the method is demonstrated by the comparisons.

11. THEORY OP THE TRUNCATION ERROR CANCELLATION (TEC) METHOD

The effects of truncation errors on the stabil1ty of fintte difference equations have been described in Ref. 2. These effects are brieñly reviered here to the extent that they are preliminary for the stabllity trethod proposed. Th: method is completely general; the description, however, centers on the continuty equation as a specific 1llustration. A simplified derivation is given here to indicate the general Idea of the schette. A more comprehensive derivation is presented in Appendix $A$.

In one dimension, the continutey equation is

$$
\begin{aligned}
& D E(i) \equiv \frac{\partial j}{\partial t}+\frac{3 E u}{\partial x} \\
& D E(D)=0
\end{aligned}
$$

where DE(o) repreoenta the partial differentlal equation, $p$ is the mass density, $t$ is the tiwe, and t is the velocity coaponent in the $x$-dizection. The finite difference approximation FD( $(0)$ is used for Dif(o) so that

$$
F(0)=D E(0)+c . c .
$$

The truncation errors, t.e., are the h1gher order teras in a Taylor series expansion of $F(p)$ about the poine, $x=16 x$ and $t=n t$; the zeroth order cerms in the expansion yleld $D E(0)$. 
For consideration of stability, we need only those truncation errors that lead to diffusion of $0,1.2 .$, errors of the fors $\varepsilon \frac{\partial^{2} p}{\partial x^{2}}$ where $\varepsilon$ is the diffusion coefficlent. Thus we may rewrite Eq. (2.2) In the form

$$
D E(\rho)=F D(\rho)+\varepsilon \frac{\partial^{2} \rho}{\partial x^{2}}+o \cdot t . e .
$$

where we have transposed the truncation error terms, wth the last term on the right hand alde representIng the other truncation errors, Hirt's stab1lity theory state that $F D(\rho)=018$ numerically inszable, having an exponentially growing solution, when $\varepsilon$ is negative. Thls can be seen from Eq. (2.3) when geglecting the other truntation error terns,

$$
D E(p)=\varepsilon \frac{\partial^{2} \rho}{\partial x^{2}}
$$

where a regative vaiue of $\varepsilon$ leada to exponential grouth in the solution of the partial differential equation.

The task then is to obtain aunerical etability In the calculations by locally sensing the algebralc sign and magnitude of $c$ and, proriding the conditans warrant 1t, to include an expltcit diffusion term in the finite difference equation to cancel the negatse diffusion. This terw is written syabolically as

$$
\operatorname{FD}\left(A \frac{\partial^{2} \rho}{\partial x^{2}}\right)=A \frac{\partial^{2} \rho}{\partial x^{2}}+0 . t \cdot c
$$

as In Eq. (2.2) where A is a diffusion coefficient to be defined later. Inserting this Into Eq. (2.3) yle1ds

$$
\begin{aligned}
\operatorname{DE}(\rho) \sim \operatorname{FD}(\rho) & -\operatorname{ED}\left(\Lambda \frac{\partial^{2} \rho}{\partial x^{2}}\right) \\
& +(A+C) \frac{\partial^{2} p}{\partial x^{2}}+0 . t . e .
\end{aligned}
$$

and the new difference equation to be aolved is

$$
F D(0)-E D\left(A \frac{\partial^{2} p}{\partial x^{2}}\right)-0
$$

which resules in

$$
\operatorname{BE}(\nu)=(A+c) \frac{\partial^{2} p}{\partial x^{2}}+0 . \cdot c .
$$

The coefficlent $A$ is chosen such that $A+\varepsilon>0$. Th1s inequality is necessary in accord with Hirt's stabil ity theory since we solve $\mathrm{Eq}$. (2.7) Instead of $F D(p)=0$.

Choosing A such that the inequality is statisfled is necessary for the stability of Eq. (2.7). Negative values of $E$, which are a source of instabil1ty, are countered with positive values of A. Po:s1tive values of $\varepsilon$ are stabilizing and negative values of $A$ can reduce the effective diffuston coefficient. With respect to this latter point, we have found in practice that negative values of $A$ tend to enhance local curvatures in the density field, 1.e., local peaks and troughs, until balanced by contributions from the convective term $\frac{\partial \rho u}{\partial x}$. The effect of this Is to give rise to dispersive errors since they are proporitinal to the rate of change of curvature. These errors, although not destabllizing per se, can cause a signiflcant loss of accuracy.

It 1 s frequently desired to cast the finite difference form of the diffusion term into conservation form. Th1s is accomplished with no additional. complication when $\frac{\partial A}{\partial x}$ does not contain terms leading to further $p$ diffusion. In this case the conservative and non-conservative forms are interchangeable so that we can write

$$
F D(0)-F D\left[\frac{\partial}{\partial x}\left(\Lambda \frac{\partial \rho}{\partial x}\right)\right]=0
$$

In place of Eq. (2.7).

In the event that $\frac{\partial A}{3 x}$ does lead to $D$ ditfigsion, we intruduce a second diffusion coefficient $A^{\prime}$ and resirite Eq. (2.9) as

$$
F D(\rho)-F D\left\{\frac{\partial}{\partial x}\left[\left(A+A^{\prime}\right) \frac{\partial \rho}{\partial x}\right]\right\}=0
$$

where $A^{*}$ is deternin*d from the differential equation

$$
\left(\frac{\partial A}{\partial x}\right)_{0} \frac{\partial \rho}{\partial x}+\frac{\partial}{\partial x}\left(A^{\prime} \frac{\partial \rho}{\partial x}\right)=0 .
$$

The factor $\left(\frac{\partial A}{\partial x}\right)_{D}$ refers to that por 1 on of $\frac{\partial A}{\partial x}$ leading to f diffusion. The solution of Eq. (2.11) is

$$
A^{\prime}=\left(\frac{\partial \rho}{\partial x}\right)^{-1}\left[\int\left(\frac{\partial A}{\partial x}\right)_{0}\left(\frac{\partial \rho}{\partial x}\right) d x+c\right]
$$


where $\mathrm{C}$ is the constant of integration. The constant has no effect in Eq. (2.10) since we want

$\partial\left[A^{\prime} \partial \rho / \partial x\right] / \partial x ;$ hence $1 t$ is set to zero and the expression for $A^{\prime}$ becomes

$$
A^{\prime}=\left(\frac{\partial \rho}{\partial x}\right)^{-1} \int\left(\frac{\partial A}{\partial x}\right)_{D} \frac{\partial \rho}{\partial x} d x,
$$

evaluated locally in the computing mesh.

In summary, we propose to solve Eq. $(2.10)$ as an approxfination to

$$
\operatorname{DE}(\rho)=0,
$$

where $A^{\prime}$ is given In Eq. (2.13) and A satisfies the inequality $\mathrm{A}+\varepsilon>0$.

\section{APPLICATION OF THE TEC METHOD}

\section{A. D1ffusional Truncation Errors for the RICE Equationg}

The preceding section described, by means of a simple example, the general approach to applying this technique. In the remainder of the report, we shall show in dratall how the technique is applied to the difference equations in the RICE $^{3}$ computer code and the Increased accuracy attained with 1t. RICE was chosen because of 1 ts general applicabllity for colving a broad spectrum of transient, two-dimensional, wixing and chemically reacting flow problems and because its difference equations are typical of other Eulerian Eluid dynamics programs. In this section, we derive the relevant truncation error diffuston terms from the finite difference approximations to the mass, momenta, specific internal energy and species transport equations. In addition to the diffuaive errors given here, a complete listing of the low order errors in the absence of transport effeces 18 presented in Append $1 x$ B.

For the RICE difference equations, the fluld variables are located as shown in Figure $1 . Q_{1}^{j}$ represents the densiey $\rho_{1}^{j}$, pressure $p_{1}^{j}$, specific intcrnal energy $I_{1}^{j}$, and spectes denstey $\left(p_{\alpha}\right)_{1}^{j}$ for apecies $a$, which are stored at the cell center. Velocity components $u_{i+\frac{1}{2}}^{j}$ and $v_{1}^{j+\frac{1}{2}}$ in the $x$ and $y$ directions are stored at the center of the right and cop boundartes respectively. The indices, 1 and $f$ correapond to the 1 th column and $j \underline{\text { th }}$ row of computetional cells.

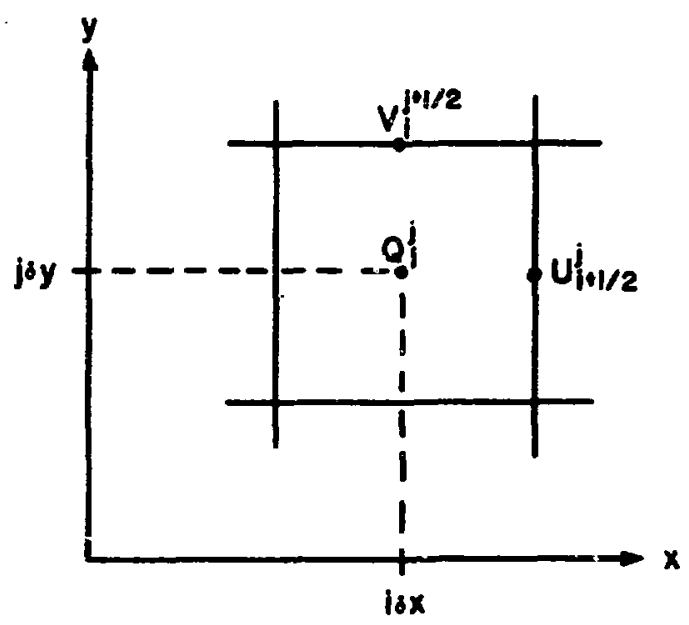

Figure 1. Location of variables in the computational mesh. $Q_{i}^{j}$ represents the density $\rho_{i}^{j}$, pressure $p_{1}^{j}$, spectfic internal energy $I_{\perp}^{j}$, and spectes density $\left(p_{\alpha}\right)_{i}^{j}$ for species which are stored at the cell center. The velocity components $u_{1+\frac{1}{2}}^{j}$ and $v_{1+\frac{1}{2}}^{j}$ in the $x$ and $y$ directions are stored on the cell boundaries.

The fintte difference expression for the RICE mass equation in Cartesian coordinates is

$$
\begin{aligned}
F D(\rho) & =\left[{ }^{n+1} \rho_{1}^{j}-\rho_{1}^{j} \mid / \delta t+\theta^{n+1}\left\{\left(\left(\rho_{1}^{j}+\rho_{1+1}^{j}\right) u_{1+\frac{1}{2}}^{j}\right.\right.\right. \\
& -\left(\rho_{1}^{j}+\rho_{1-1}^{j}\right) u_{1-\frac{1}{2}}^{j}|/ 2 \delta x+|\left(\rho_{1}^{j}+\rho_{1}^{j+1}\right) v_{1}^{j+\frac{1}{2}} \\
& \left.-\left(\rho_{1}^{j}+\rho_{1}^{j-1}\right) v_{1}^{j-\frac{1}{2}} \mid / 2 \delta y\right\} \\
& +(1-\theta)\left\{\left(\rho_{1}^{j}+\rho_{1+1}^{j}\right) u_{1+\frac{1}{2}}^{j}\right. \\
& \left.-\left(\rho_{j}^{j}+\rho_{1-1}^{j}\right) u_{1-\frac{1}{2}}^{j}\right) / 2 \delta x+\left(\left(\rho_{1}^{j}+\rho_{1}^{j+1}\right) v_{1}^{j+\frac{1}{2}}\right. \\
& \left.\left.-\left(\rho_{1}^{j}+\rho_{1}^{j-1}\right) v_{1}^{j-\frac{1}{2}}\right] / 2 \delta y\right\} .
\end{aligned}
$$

The parameter $\theta$ ranges from 0.0 to 1.0 and is a measure of the implicitness of the calculation, 1.e., $\theta=0.0$ is fully expllcte and $\theta=1.0$ is fully $1 \mathrm{~m}-$ plicit. The time level Buperscript $(n+1)$ refers to quantities evaluated at the advanced time. When the time level superscript is omitted, time level $n$ is Impl 1ed. 
We expand the finite difference approximation to the mass conservation equation about the point $(1, j$, if Typical expansions are

$$
\begin{aligned}
& n+1 \rho_{1}^{j}=n_{\rho_{1}^{j}}+\frac{\partial \rho}{\partial t} \delta t+\frac{\partial^{2} \rho}{\partial t^{2}} \frac{\delta t^{2}}{2}+\ldots, \\
& \rho_{1+1}^{j}=\rho_{1}^{j}+\frac{\partial \rho}{\partial x} \delta x+\frac{\partial^{2} \rho}{\partial x^{2}} \frac{\delta x^{2}}{2}+\frac{\partial^{3} \rho}{\partial x^{3}} \frac{\delta x^{3}}{6}+\ldots, \\
& \rho_{1}^{j+1}=\rho_{1}^{j}+\frac{\partial \rho}{\partial y} \delta y+\frac{\partial^{2} \rho}{\partial y^{2}} \frac{\delta y^{2}}{2}+\frac{\partial^{3} \rho}{\partial y^{3}} \frac{\delta y^{3}}{6}+\ldots, \\
& u_{1+\frac{1}{j}}^{j}=u_{1}^{j}+\frac{\partial u}{\partial x} \frac{\delta x}{2}+\frac{\partial^{2} u}{\partial x^{2}} \frac{\delta x^{2}}{8}+\frac{\partial^{3} u}{\partial x^{3}} \frac{\delta x^{3}}{48}+\ldots, \\
& v_{1}^{j+\frac{1}{2}}=v_{1}^{j}+\frac{\partial v}{\partial y} \frac{\delta y}{2}+\frac{\partial^{2} v}{\partial y^{2}} \frac{\delta y^{2}}{8}+\frac{\partial^{3} y}{\partial y^{3}} \frac{\delta y^{3}}{48}+\ldots .
\end{aligned}
$$

Inserting these expressions tneo EG. (3.1) and rataining only the lowest order time and space exrors in the diffusion coefflcients results in

$$
\begin{aligned}
\frac{\partial \rho}{\partial t}+\frac{\partial \rho u}{\partial x}+\frac{\partial \rho v}{\partial y} & =\operatorname{FD}(\rho)+(2 \theta-1) \frac{\delta t}{2}\left[\left(u^{2}\right.\right. \\
& \left.\left.+c^{2}\right) \frac{\partial^{2} \rho}{\partial x^{2}}+\left(v^{2}+c^{2}\right) \frac{\partial^{2} p}{\partial y^{2}}\right] \\
& -\frac{\delta x^{2}}{4} \frac{\partial u}{\partial x} \frac{\partial^{2} \rho}{\partial x^{2}}-\frac{\delta y^{2}}{4} \frac{\partial v}{\partial y} \frac{\partial^{2} \rho}{\partial y^{2}} \\
& + \text { o.t.e. }
\end{aligned}
$$

In which $c^{2}$ is the square of the adiabatic sound speed. Note that the choice of $\theta=0.5$ ellminates the first order time error in the equation.

The finite difference approximation to the $x-$ direct: on momentum equation is given by

$$
\begin{aligned}
& F D(\rho u)=\left[{ }^{n+1}(\rho u)_{1+\frac{1}{2}}^{j}-(\rho u)_{1+\frac{1}{2}}^{j}\right] / \delta t \\
& +\left[\left(\rho u^{2}\right)_{1+1}^{j}-\left(\rho u^{2}\right)_{1}^{j} j^{7} / \delta x+\left[(\rho u v)_{1+\frac{1}{2}}^{j+\frac{1}{2}}\right.\right. \\
& \left.-(\rho u v)_{i+\frac{1}{2}}^{j-\frac{1}{2}}\right] / \delta y+\left[\phi\left(\bar{P}_{i+1}^{j}-\bar{P}_{i}^{i}\right)\right. \\
& \left.+(1-\phi)\left(\bar{P}_{1+1}^{j}-\bar{P}_{1}^{j}\right)\right] / \delta x+\left[\left(\sigma_{x x}\right)_{1}^{j}\right. \\
& \left.-\left(\sigma_{x x x}\right)_{1+1}^{j}\right]^{1 / \delta x}+\left[\left(\sigma_{x i y}\right)_{1+\frac{1}{2}}^{j-\frac{1}{2}}\right. \\
& \left.-\left(\sigma_{x y}\right)_{1+\frac{1}{y}}^{j+\frac{1}{2}}\right] / \delta y \text {. }
\end{aligned}
$$

The quantity $\overrightarrow{\mathrm{P}}_{1}^{\mathrm{j}}$ is a partially, time-advanced pressure

$$
\bar{p}_{1}^{j}=p_{1}^{j}+\left(c^{2}\right)_{1}^{j}\left(n+1 \rho_{1}^{j}-\rho_{1}^{j}\right)
$$

and the parameter $\phi$ is similar to $\theta$ in Eq. (3.1.). The womentum flux terms are given by

$$
\begin{aligned}
& \left(\rho u^{2}\right)_{1}^{j}=\rho_{i}^{j}\left(u_{1+\frac{1}{2}}^{j}+u_{1-\frac{1}{2}}^{j}\right)^{2} / 4, \\
& (\rho u v)_{i+\frac{1}{2}}^{j+\frac{1}{2}}=\left(\rho_{1}^{j}+\rho_{i+1}^{j}+\rho_{1+1}^{j+1}+\rho_{1}^{j+1}\right) \\
& \left(u_{i+\frac{1}{2}}^{j}+u_{1+\frac{1}{2}}^{j+1}\right)\left(v_{1}^{j+\frac{1}{2}}+v_{1+1}^{j+\frac{1}{2}}\right) / 16,
\end{aligned}
$$

and $\sigma_{x x}$ and $\sigma_{x y}$ are the viscous stress tensor components given by

$$
\begin{aligned}
\left(\sigma_{x x}\right)_{i}^{j} & =2 \mu_{1}^{j}\left(u_{i+\frac{1}{2}}^{j}-u_{1-\frac{1}{2}}^{j}\right) / \delta x+\lambda_{i}^{j}\left[\left(u_{i+\frac{1}{2}}^{j}\right.\right. \\
& \left.\left.-u_{i-\frac{1}{2}}^{j}\right) / \delta x+\left(v_{1}^{j+\frac{1}{2}}-v_{1}^{j-\frac{1}{2}}\right) i \delta y\right], \\
\left(\sigma_{x y}\right)_{i+\frac{1}{2}}^{j+\frac{1}{2}} & =\frac{1}{4}\left(\mu_{i}^{j}+\mu_{i+1}^{j}+\mu_{i+1}^{j+1}+\mu_{i}^{j+1}\right)\left[\left(u_{i+\frac{1}{2}}^{j+1}\right.\right. \\
& \left.\left.-u_{i+\frac{1}{2}}^{j}\right) / \delta y+\left(v_{i+1}^{j+\frac{1}{2}}-v_{i}^{j+\frac{1}{2}}\right) / \delta x\right],
\end{aligned}
$$

where $\mu$ and $\lambda$ are the coefficients of shear and bulk viscosity and are stored at the cell center.

Substituting the appropriate expansions about the point $\left(1+\frac{1}{2}, j, n\right)$ Into Eq. (3.4), we obtain

$$
\begin{aligned}
\frac{\partial \rho u}{\partial t}+\frac{\partial \rho u^{2}}{\partial x} & +\frac{\partial \rho u v}{\partial y}+\frac{\partial p}{\partial x}-\frac{\partial \sigma x}{\partial x}-\frac{\partial \sigma x y}{\partial y}=F D(\rho u) \\
& +\frac{\delta t}{2}\left\{\rho\left[(2 \phi-1) c^{2}-3 u^{2}\right] \frac{\partial^{2} u}{\partial x^{2}}\right. \\
& \left.-\rho v^{2} \frac{\partial^{2} u}{\partial y}\right\}-\frac{\delta x^{2}}{2}\left(\frac{\partial \rho u}{\partial x}\right) \frac{\partial^{2} u}{\partial x^{2}} \\
& -\frac{\delta y^{2}}{4}\left(\frac{\partial \rho v}{\partial y}\right) \frac{\partial^{2} u}{\partial y^{2}}+\text { o.t.e., }
\end{aligned}
$$

where we have neglected the low order diffustonal errors that arise from the spatial variation of the viscosity coeficients since these are generally small compared to the diffusional terms retalned. For stabllity, we consider only u diffusion, since Bubtraction of the mass conservation equation from the left hand side of Eq. (3.8) removes the density time derivative. 
An equation simflar to $\mathrm{gq.} \mathrm{(3.8)} \mathrm{IE} \mathrm{derived} \mathrm{for}$ the $y$-direction momentum by expanding $F D(\rho v)$ about the point $\left(1, j+\frac{1}{2}, n\right)$ :

$$
\begin{aligned}
\frac{\partial \rho v}{\partial t} & +\frac{\partial \rho u v}{\partial x}+\frac{\partial \rho v^{2}}{\partial y}+\frac{\partial p}{\partial y}-\frac{\partial \sigma x y}{\partial x}-\frac{\partial \sigma y y}{\partial y}=F D(\rho v) \\
& +\frac{\delta t}{2}\left\{-\rho u^{2} \frac{\partial^{2} v}{\partial x^{2}}+\rho\left[(2 \phi-1) c^{2}-3 v^{2}\right] \frac{\partial^{2} v}{\left.\partial y^{2}\right\}}\right. \\
& -\frac{\delta x^{2}}{4}\left(\frac{\partial \rho u}{\partial x}\right) \frac{\partial^{2} v}{\partial x^{2}}-\frac{\delta y^{2}}{2}\left(\frac{\partial \rho v}{\partial y}\right) \frac{\partial^{2} v}{\partial y^{2}}+\text { o.t.e }
\end{aligned}
$$

In the absence of enthalpy diffusion and cheinistry, the finite difference equation for the internal energy density, $\rho I$, is

$$
\begin{aligned}
& F D(\rho I)=\left|n+1_{\rho I}^{j}-\rho_{i}^{j}\right|^{j} / \delta t+\mid n+1_{u_{i+1}^{j}}^{j}\left(\rho I_{1}^{j}\right. \\
& \left.+\rho I_{1+1}^{j}\right)-{ }^{n+1} u_{i-\frac{1}{2}}^{j}\left(\rho l_{i}^{j}+\rho I_{i-1}^{j}\right) \mid / 2 \delta x \\
& +\mid n+1 v_{1}^{j+\frac{1}{2}}\left(\rho_{1}^{j}+\rho I_{1}^{j+1}\right)-{ }^{n+1} v_{1}^{j-\frac{l}{2}}\left(\rho I_{1}^{j}\right. \\
& \left.\left.+\rho I_{1}^{j-1}\right)\right] / 2 \delta y+\left[\bar{p}_{1}^{j}-\left(o_{x x}\right)_{1}^{j}\right]\left\{\left({ }^{n+1} u_{1+\frac{1}{2}}^{j}\right.\right. \\
& \left.\left.-{ }^{n+1} u_{t-\frac{1}{2}}^{j}\right) / \delta x\right)+\left(\vec{p}_{1}^{j}-\left(a_{y y}\right)_{1}^{j}\right) \mid\left({ }^{n+1} v_{1}^{j+1 / 2}\right. \\
& \left.-{ }^{n+1} v_{i}^{j-\frac{1}{2}}\right) / \delta y \mid-\left(\sigma_{x y}\right)_{1}^{j}\left[\left({ }^{n+1} u_{i+\frac{1}{2}}^{j+1}\right.\right. \\
& \left.+{ }^{n+1} u_{i-\frac{1}{2}}^{j+1}-n+1 u_{i+\frac{1}{2}}^{j-1}-n+1 u_{i-\frac{1}{2}}^{j-1}\right) / 4 \delta y \\
& +\left(n+1 v_{i+1}^{j+\frac{1}{2}}+{ }^{n+1} v_{1+1}^{j-\frac{1}{2}}-n+1 v_{1-1}^{j+\frac{1}{2}}-{ }^{n+1} v_{1-1}^{j-\frac{1}{2}}\right) \\
& 14 \delta x]-\left[k_{1+\frac{1}{2}}^{j}\left(I_{i+1}^{j}-I_{i}^{j}\right)-k_{1-i z}^{j}\left(I_{i}^{j}\right.\right. \\
& \left.\left.-I_{1-1}^{j}\right)\right] / \delta x^{2}-\left[k_{1}^{j+\frac{1}{2}}\left(I_{1}^{j+1}-I_{1}^{j}\right)\right. \\
& \left.-k_{1}^{j-k}\left(I_{i}^{j}-I_{i}^{j-1}\right)\right] / \delta y^{2}
\end{aligned}
$$

where $k$ is related to the thermal conductivity coefficlent and is stored at the cell center. The solution for ${ }^{n+1} \mathrm{fI}_{i}^{j}$ is purely explicit using the time advanced density and velocity flelds.
A Taylor series expansion of Eq. (3.10) about the point $(i, j, n)$ : ylelds

$$
\begin{aligned}
\frac{\partial \rho I}{\partial t} & +\frac{\partial \rho u I}{\partial x}+\frac{\partial \rho v I}{\partial y}+\left(p-\sigma_{x x}\right) \frac{\partial u}{\partial x}+\left(p-\sigma_{y y}\right) \frac{\partial v}{\partial y} \\
& -\sigma_{x y}\left(\frac{\partial u}{\partial y}+\frac{\partial v}{\partial x}\right)-\frac{\partial}{\partial x}\left(k \frac{\partial I}{\partial x}\right)-\frac{\partial}{\partial y}\left(k \frac{\partial I}{\partial y}\right)=F D(\rho I) \\
& +\frac{\delta t}{2}\left(-\rho u^{2} \frac{\partial^{2} I}{\partial x^{2}}-\rho v^{2} \frac{\partial^{2} I}{\partial y^{2}}\right)-\frac{\delta x^{2}}{4}\left(\rho \frac{\partial u}{\partial x}\right. \\
& \left.+2 u \frac{\partial \rho}{\partial x} \frac{\partial^{2} I}{\partial x^{2}}\right)-\frac{\delta y^{2}}{4}\left(\rho \frac{\partial v}{\partial y}+2 v \frac{\partial \rho}{\partial y} \frac{\partial^{2} I}{\partial y^{2}}\right) \\
& + \text { o.t.e., }
\end{aligned}
$$

where analogous to the treatment of the variations in viscosity coefficlents in $\mathrm{Eq} .(3.8)$, we have neglected the low order diffusional errors that arise frow the spatial variation of the coefficient $k$.

The finite difference approximation to the species transport equation neglecting molecular diffustion is

$$
\begin{aligned}
& \operatorname{FD}\left(\rho_{\alpha}\right)=\left[{ }^{n+1}\left(\rho_{\alpha}\right)_{i}^{j}-\left(\rho_{\alpha}\right)_{i}^{j}\right] / \delta t+\left\{\left[\left(\rho_{\alpha}\right)_{i}^{j}\right.\right. \\
& \left.\left.+\left(\rho_{\alpha}\right)^{j}\right]^{n+1}\right]_{i+\frac{1}{2}}^{j}-\left[\left(\rho_{\alpha}\right)_{i+1}^{j}-\left(\rho_{\alpha}\right)_{i}^{j}\right] \\
& \left(n+1 u_{i+\frac{1}{2}}^{j}\right)^{2} \delta t / \delta x-\left[\left(\rho_{\alpha}\right)_{i}^{j}+\left(\rho_{\alpha}\right)_{i-1}^{j}\right] \\
& n+1_{u_{i-\frac{1}{2}}^{j}}+\left[\left(\sigma_{\alpha}\right)_{i}^{j}-\left(o_{\alpha}\right)_{i-1}^{j}\right]\left(n+1_{u_{i-\frac{1}{2}}^{j}}\right)^{2} \\
& \delta t / \delta x\} / 2 \delta x+\left\{\left[\left(o_{\alpha}\right)_{1}^{j}+\left(\rho_{\alpha}\right)_{1}^{j+1}\right]^{n+1} v_{i}^{j+\frac{1}{2}}\right. \\
& -\left[\left(i_{\alpha}\right)_{1}^{j+1}-\left(\rho_{\alpha}\right)_{1}^{j}\right]\left({ }^{n+1} v_{i}^{j+\frac{1}{2}}\right)^{2} \delta t / \delta y \\
& -\left[\left(\rho_{\alpha}\right)_{i}^{j}+\left(o_{\alpha}\right)_{i}^{j-1}\right]^{n+1} v_{i}^{j-\frac{k}{2}}+\left[\left(\rho_{\alpha}\right)_{i}^{j}\right. \\
& \left.\left.-\left(\rho_{\alpha}\right)_{i}^{j-1}\right]\left(n+1 v_{i}^{j-k_{2}}\right)^{2} \delta t / \delta y\right\} / 2 \delta y .
\end{aligned}
$$

Here, the subscript $\alpha$ refers to the spectes $\alpha$ and the solution for ${ }^{n+1}\left(o_{\alpha}\right)_{i}^{j}$, just as in the preceding case for the internal energy, is purely explicit.

Taylor geries expansions for this equation result in

$$
\begin{aligned}
\frac{\partial \rho_{\alpha}}{\partial t} & +\frac{\partial \rho_{\alpha} u}{\partial x}+\frac{\partial \rho_{\alpha} v}{\partial y}=\operatorname{FD}\left(\rho_{\alpha}\right)-\frac{\delta x^{2}}{4} \frac{\partial u}{\partial x} \frac{\partial^{2} \rho_{\alpha}}{\partial x^{2}} \\
& -\frac{\delta y^{2}}{4} \frac{\partial v}{\partial y} \frac{\partial^{2} \rho_{\alpha}}{\partial y^{2}}+\text { o.t.e. }
\end{aligned}
$$


Because of the time-centering of the convection terms in Eq. (3.12), the lowest time error is of second order and is not specified here because it is usually negligible in comparison to the spatial errors.

\section{B. Stabilization of the RICE Equations}

The schere for stabilizing the RICE equations is presented here in detall. For each equation the conditions $\left(A+\varepsilon_{x}\right)>0$ and $\left(B+\varepsilon_{y}\right)>0$ are satisfied by choosing $A$ and $B$ according to

$$
\begin{aligned}
& A= \begin{cases}-(1-\xi) \varepsilon_{x} & \varepsilon_{x}>0 \\
-(1+\xi) \varepsilon_{x} & \varepsilon_{x}<0,\end{cases} \\
& B= \begin{cases}-(1-\xi) \varepsilon_{y} & \varepsilon_{y}>0 \\
-(1+\xi) \varepsilon_{y} & \varepsilon_{y}<0,\end{cases}
\end{aligned}
$$

where $\varepsilon_{x}$ and $\varepsilon_{y}$ are approximated by the low order truncation error diffusion coefficlents for the $x$ and $y$ directions and $B$ is the $y$-counterpart of $A$. The $\varepsilon^{\prime} s$ are calculated as $\varepsilon=F D(\varepsilon)$ consistent with our finite difference approximations. The parameter $\xi$ has the range $0<\xi<1$ and is used to control the amount of effective diffusion after the low order diffusional truncation errors are exactly cancelled. The additional terms to be added to the finite difference equations presented in Sec. IIIA are summarized as follows.

1. Mass equation.

The coefficients $\varepsilon_{x}$ and $\varepsilon_{y}$ are given by

$$
\begin{aligned}
\varepsilon_{x_{1+\frac{1}{2}}}^{j} & =(2 \theta-1) \delta t / 2\left\{\left(u_{1+t_{2}}^{j}\right)^{2}+1 / 2\left[\left(c^{2}\right)\right.\right. \\
& \left.\left.+\left(c^{2}\right)_{i}^{j}\right]\right\}-\left(u_{i+3 / 2}^{j}-u_{i-\frac{1}{2}}^{j}\right) \delta x / 8, \\
\varepsilon_{y_{1}^{j+\frac{1}{2}}}^{j} & =(2 \theta-1) \delta t / 2\left\{\left(v_{i}^{j+\frac{1}{2}}\right)^{2}+1 / 2\left[\left(c^{2}\right)_{i}^{j}\right.\right. \\
& \left.\left.+\left(c^{2}\right)_{i}^{j+1}\right]\right\}-\left(v_{1}^{j+3 / 2}-v_{1}^{j-\frac{1}{2}}\right) \delta x / 8 .
\end{aligned}
$$

The equation to be solved for the mass density is

$$
\begin{gathered}
\left.F D(\rho)-A_{i+\frac{1}{2}}^{j}\left(\rho_{i+1}^{j}-\rho_{i}^{j}\right)-A_{i-\frac{1}{2}}^{j}\left(\rho_{i}^{j}-\rho_{i-1}^{j}\right)\right] \\
/ \delta x^{2}-B_{i}^{j+\frac{1}{2}}\left(\rho_{i}^{j+1}-\rho_{i}^{j}\right)-B_{i}^{j-\frac{1}{2}}\left(\rho_{i}^{j}\right. \\
-\rho_{i}^{j-1} j_{j}^{j} / \delta y^{2}=0 .
\end{gathered}
$$

where $F D(\rho)$ is given by Eq. (3.1), and the coefficients $A$ and $B$ are determined by using Eqs. (3.16) and (3.i7) in Eqs. (3.14) and (3.15).

2. Momentum equations.

For tha $x$-component, we have

$$
\begin{aligned}
\varepsilon_{x_{i+1}}^{j} & =\rho_{i+1}^{j}(2 \phi-1)\left(c^{2}\right)_{i+1}^{j}-3\left(u_{i+3 / 2}^{j}\right. \\
& +u_{i+\frac{1}{2} j}^{j} i^{2} / 4 i \delta t / 2-\left(\rho u_{i+3 / 2}^{j}-\rho u_{i+\frac{1}{2}}^{j}\right) \delta x / 2,
\end{aligned}
$$

$$
\begin{aligned}
\varepsilon_{y_{i+\frac{1}{2}}^{j+\frac{1}{2}}}= & -\left(\rho_{1}^{j}+\rho_{j+1}^{j}+\rho_{1+1}^{j+1}+\rho_{1}^{j+1}\right)\left(v_{i}^{j+l_{2}}\right. \\
& \left.+v_{i+1}^{j+\frac{1}{2}}\right)^{2} \delta t / 32-\left(\rho v_{1}^{j+3 / 2}+\rho v_{i+1}^{j+3 / 2}\right. \\
& \left.-\rho v_{1}^{j-\frac{1}{2}}-\rho v_{1 \div 1}^{j-b_{i}}\right) \delta y / 16 .
\end{aligned}
$$

The $x$-component of the romentum density is calculated from

$$
\begin{aligned}
F D(\rho u) & -\left\{\left[A_{i+1}^{j}+\left(A^{\prime}\right)_{i+1}^{j}\right]\left(u_{1+3 / 2}^{j}-u_{i+\frac{1}{2}}^{j}\right)\right. \\
& \left.-\left[A_{i}^{j}+\left(A^{\prime}\right)_{1}^{j}\right]\left(u_{i+\frac{1}{2}}^{j}-u_{i-\frac{1}{2}}^{j}\right)\right\} / \delta x^{2} \\
& +\left[B_{1+\frac{1}{2}}^{j+\frac{1}{2}}\left(u_{i+\frac{1}{2}}^{j+1}-u_{1+\frac{1}{2}}^{j}\right)-B_{1+\frac{1}{2}}^{j-\frac{1}{2}}\left(u_{i+\frac{1}{1}}^{j}\right.\right. \\
& \left.\left.-u_{i+\frac{1}{2}}^{j-1}\right)\right] / \delta y^{2}=0
\end{aligned}
$$

In which $\mathrm{FD}(\rho \mathrm{u})$ is given by Eq. (3.4). In this equation, $\frac{\partial A}{\partial x}$ itself leads to diffusion of $u$ velocity and hence, $A^{\prime} \neq 0$ as described in Section II. $A^{\prime}$ is determined from an Integral analogous to Eq. (2.13). The Integrand is

$$
\left(\frac{\partial A}{\partial x}\right)_{D}\left(\frac{\partial u}{\partial x}\right)=-(1 \pm \xi) \frac{\partial}{\partial x}\left|\rho\left(\frac{\partial u}{\partial x}\right)^{2}\right| \frac{\delta x^{2}}{4},
$$


where the choice of algebraic signs is governed by Eq. (3.14). The solution for $A^{\prime}$ yields

$$
A^{\prime}=(1 \pm \xi)\left(\frac{\partial u}{\partial x}\right) \rho \frac{\delta x^{2}}{4}
$$

Similar to the computation of $\epsilon_{z}, A^{\prime}$ is computed as

$$
\left(A^{\prime}\right)_{1}^{j}=-(1 \pm \xi)\left(u_{i+\frac{1}{2}}^{j}-u_{i-\frac{x}{2}}^{j}\right) \rho_{i}^{j} \frac{\delta x}{4}
$$

For the $y$-component, we have

$$
\begin{aligned}
& \varepsilon_{x_{i+\frac{1}{2}}^{j+\frac{1}{2}}}^{j}=-\left(\rho_{i}^{j}+\rho_{i+1}^{j}+\rho_{i+1}^{j+1}+\rho_{ \pm}^{j+1}\right)\left(u_{i+\frac{1}{2}}^{j}\right. \\
& \left.+u_{i+d_{2}}^{j+1}\right)^{2} \delta t / 32-\left(\rho u_{i+3 / 2}^{j}+\rho u_{i+3 / 2}^{j+1}\right. \\
& \left.-\rho u_{i-\frac{1}{2}}^{j}-\rho u_{i-\frac{1}{2}}^{j+1}\right) \delta x / 16 \text {, } \\
& \varepsilon_{y_{1}}^{j+1}=\rho_{1}^{j+1}\left[(2 \phi-1)\left(c^{2}\right)_{1}^{j+1}-3\left(v_{1}^{j+\frac{1}{2}}\right.\right. \\
& \left.+v_{i}^{j+3 / 2}\right)^{2} / 4{ }_{j} \delta / 2-\left(\rho v_{i}^{j+3 / 2}\right. \\
& \left.-\rho v_{i}^{j+l_{2}}\right) \delta y / 2
\end{aligned}
$$

The $y$-component of the momentum density is calculated from

$$
\begin{aligned}
F D(\rho v) & -\left[A_{i+\frac{1}{2}}^{j+\frac{1}{2}}\left(v_{i+1}^{j+\frac{1}{2}}-v_{j}^{j+j / z}\right)-A_{i-\frac{1}{2}}^{j+\frac{1}{2}}\left(v_{i}^{j+\frac{1}{2}}\right.\right. \\
& \left.\left.-v_{i-1}^{j+\frac{1}{2}}\right)\right] / \delta x^{2}-\left\{[ B _ { i } ^ { j + 1 } + ( B ^ { \prime } ) _ { i } ^ { j + 1 } ] \left(v_{i}^{j+3 / 2}\right.\right. \\
& \left.\left.-v_{i}^{j+\frac{1}{2}}\right)-\left[B_{i}^{j}+\left(B^{\prime}\right)_{i}^{j}\right]\left(v_{i}^{j+\frac{1}{2}}-v_{i}^{j-\frac{1}{2}}\right)\right\} \\
& / \delta y^{2}=0,
\end{aligned}
$$

where analogous to $\mathrm{Eq} .(3.21), \mathrm{B}^{\prime} \neq 0$. Similar to the expression for $A^{\prime}, B^{\prime}$ is computed as

$$
\left(B^{+}\right)_{i}^{j}=-(1 \pm \xi)\left(v_{1}^{j+l_{2}}-v_{i}^{j-\frac{1}{2}}\right) \rho_{1}^{j} \frac{\delta y}{4}
$$

and the algebraic sign choice is governed by Eq. (3.15).

3. Spectftc internal energy equation.

The expressions for $E_{x}$ and $\varepsilon_{y}$ are

$$
\begin{aligned}
& \varepsilon_{x_{i+\frac{1}{2}}}^{j}=-\left(u_{i+\frac{1}{2}}^{j}\right)^{2}\left(\rho_{i}^{j}+\rho_{i+1}^{j}\right) \delta t / 4-\left[\left(\rho_{i}^{j}\right.\right. \\
& \left.+\rho_{i+1}^{j}\right)\left(u_{i+3 / 2}^{j}-u_{i-\frac{1}{2}}^{j}\right) / 8+u_{i+\frac{1}{2}}^{j}\left(\rho_{i+1}^{j}\right. \\
& \left.\left.-p_{i}^{j}\right)\right] \delta x / 2 \\
& \varepsilon_{y_{1}^{j+\frac{1}{2}}}=-\left(v_{i}^{j+l_{2}}\right)^{2}\left(\rho_{i}^{j}+\rho_{i}^{j+1}\right) \delta t / 4-\left[\left(\rho_{i}^{j}\right.\right. \\
& \left.+\rho_{i}^{j+1}\right)\left(v_{i}^{j+3 / 2}-v_{i}^{j-\frac{1}{2}}\right) / 8+v_{i}^{j+\frac{1}{2}}\left(\rho_{i}^{j+1}\right. \\
& \left.\left.-\rho_{i}^{j}\right)\right] \delta y / 2
\end{aligned}
$$

and the finite difference equation for $c \mathrm{I}$ is

$$
\begin{aligned}
F D(\rho I) & -\left[A_{i+\frac{1}{2}}^{j}\left(I_{i+1}^{j}-I_{i}^{j}\right)-A_{i-\frac{1}{2}}^{j}\left(I_{i}^{j}-I_{i-1}^{j}\right)\right] \\
& / \delta x^{2}-\left[B_{i}^{j+\frac{1}{2}}\left(I_{1}^{j+1}-I_{i}^{j}\right)-B_{I}^{j-\frac{1}{2}}\left(I_{i}^{j}\right.\right. \\
& \left.\left.-I_{i}^{j-1}\right)\right] / \delta y^{2}=0
\end{aligned}
$$

where $\mathrm{FD}(\rho \mathrm{I})$ is given by Eq. (3.10).

\section{Species transport equation.}

The spectes transport equation spatial diffusion terms are given in Eq. (3.13) and are computed as

$$
\begin{aligned}
& \varepsilon_{x_{1+1 / 2}}^{j}=-\left({ }^{n+1} j_{i+3 / 2}^{j}-n+1 u_{1-\frac{1}{2}}^{j}\right) \delta x / 8, \\
& \varepsilon_{y_{1}^{j+x_{2}}}^{j}=-\left({ }^{n+1} v_{i}^{j+3 / 2}-{ }^{n+1} v_{i}^{j-\frac{1}{2}}\right) \delta y / 8,
\end{aligned}
$$

The fintte difference equation to be solved for the species density it

$$
\begin{aligned}
F D\left(\rho_{\alpha}\right) & -\left\{A_{I+\frac{1}{2}}^{j}\left[\left(\rho_{\alpha}\right)_{i+1}^{j}-\left(\rho_{\alpha}\right)_{1}^{j}\right]-A_{ \pm-\frac{1}{2}}^{j}\left[\left(\rho_{\alpha}\right)_{i}^{j}\right.\right. \\
& \left.\left.-\left(\rho_{\alpha}\right)_{ \pm-1}^{j}\right]\right\} / \delta x^{2}-\left\{B _ { i } ^ { j + \frac { 1 } { 2 } } \left[\left(\rho_{\alpha}\right)_{i}^{j+1}\right.\right. \\
& \left.\left.-\left(\rho_{\alpha}\right)_{i}^{j}\right]-B_{i}^{j-\frac{1}{2}}\left[\left(\rho_{\alpha}\right)_{i}^{j}-\left(\rho_{\alpha}\right)_{1}^{j-1}\right]\right\} / \delta y^{2} \\
& =0
\end{aligned}
$$

where $\mathrm{FD}\left(\rho_{\alpha}\right)$ is given by Eq. (3.12). 


\section{DIFFUSIONAL LIMITS}

In this section the diffusional limits imposed on the time step are established for the TEC method. The method usually allows a larger time step than typlcal artifictal viscosity schemes and the reasons for this are discussed.

The effective diffusion coefficlents introduced Into the conservation equations after the low order, diffusional truncation errors are exactly cancelled are

$$
A_{\text {eff }}=\xi\left|\varepsilon_{x}\right| \text { and } B_{\text {eff }}=\xi\left|\varepsilon_{y}\right| \text {, }
$$

according to Eqs. (3.14) and (3.15). The diffusion terms added for numerical stabilfty are computed explicitly in Sec. IIIB for each conservation equation so that a Fourier analysis yields the requirement

$$
\delta t<\frac{(1 / 2) \delta x^{2} \delta y^{2}}{(\xi / \rho)\left[\left|\varepsilon_{y}\right| \delta x^{2}+\left|\varepsilon_{x}\right| \delta y^{2}\right]} \text {, }
$$

in the absence of transport effects. A typlcal artifictal viscosity scheme requires

$$
\delta t<\frac{(1 / 2) \delta x^{2} \delta y^{2}}{(4 \mu / 3 \rho)\left[3 \delta x^{2} / 4+\delta y^{2}\right]} \text {, }
$$

for the momentum equation, In which $\lambda=-2 / 3 \mu$.

The TEC method usually allows a larger time step than the artificlal viscosity scheme because the effective diffusion is less. The TEC method applies diffusion according to the local needs rather than uniformly in an amount sufficlent to counter the largest destabilizing truncation errors in the flow.

A further increase in time step can be achleved for flows directed primarily in one coordinate direction because of the independence of $\varepsilon_{x}$ and $\varepsilon_{y}$. For example, a flow directed in the $x$-direct Ion with $\delta x=\delta y$ would have $\varepsilon_{y} \ll \varepsilon_{x}$ and would only require

$$
\delta t<\frac{(1 / 2) \delta x^{2}}{(\xi / \rho)\left|\varepsilon_{x}\right|} \text {, }
$$

from Eq. (4.2) as compared to

$$
\delta t<\frac{(4 / 7)(1 / 2) \delta x^{2}}{(4 \mu / 3 p)}
$$

from Eq. (4.3) for an artificial viscosity scheme. With equivalent diffusion coefficlents, the TEC method would allow a $75 \%$ increase in oc for this simple example.

\section{v. NUMERICAL EXAYPLES}

In this section we present the solutions to two fiuid dynamics problems to show the accuracy of the TEC method In comparison with an artificlal viscosicy technique for stabilizing the calculations. For the first example, we calculate a problem with known solution, the channel flow problem shown schematically In F1g. 2. A perfect gas, wh speciflc heat ratio $r=1.4$, enters on the left with the pieceviselinear velocity profile shown which ranges from. $u=1.0$ at the free-slip, adiabatic walls to $u=.2$ at the center. The inflow density and specific internal energy are constant at 1.0 and .018 in nondimensional units. The ríght boundary is a continuous outflow boundary. The computational mesh consists of 31 columns and 9 rows of cells with $\delta x=\delta y=1$. The time step is $\delta t=0.2$. Inltially we set $u=1.0, v=0 ., p=1.0$, and $I \approx .018$ in the channel.

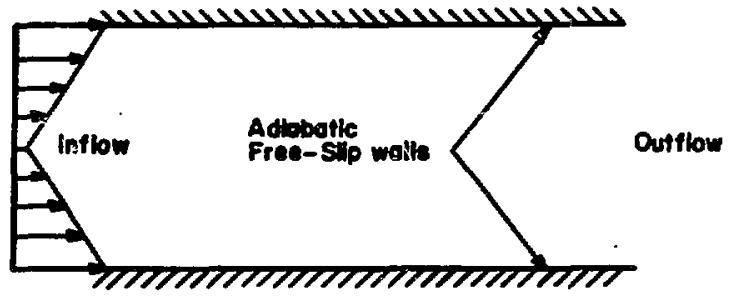

F1gure 2. Schematic of the channel flow problem.

The exact solution has no $x$-dependence at steady state so that at any position $x$ the solution corresponds to the inflow conditions. The computed steady state velocity flelds and contours of Mach number, $M$, are shown in F1gs. $3 a$ and $3 b$. F1gure $3 a$ shows the results obtalned with the TEC method. F1gure 3b shows the results obtained wth artificlal viscosity. These latter results were obtalned by solving the Navier-Stokes equations with $\mu / \rho=\lambda / \rho$ $=.1$ and $k=2.5 \mu / \rho$ where $\mu$ and $\lambda$ are the shear and bulk viscosities used in $\mathrm{Eq} .(3.7)$ and $k$ is the thermal conductivity. These values are essentially the minima necessary for stability and are compared to a cholce of $\mu, \lambda$, and $k=0$ for the TEC method. For both calculations, the continulty equation was stabilized using the truncation eiror approach. 

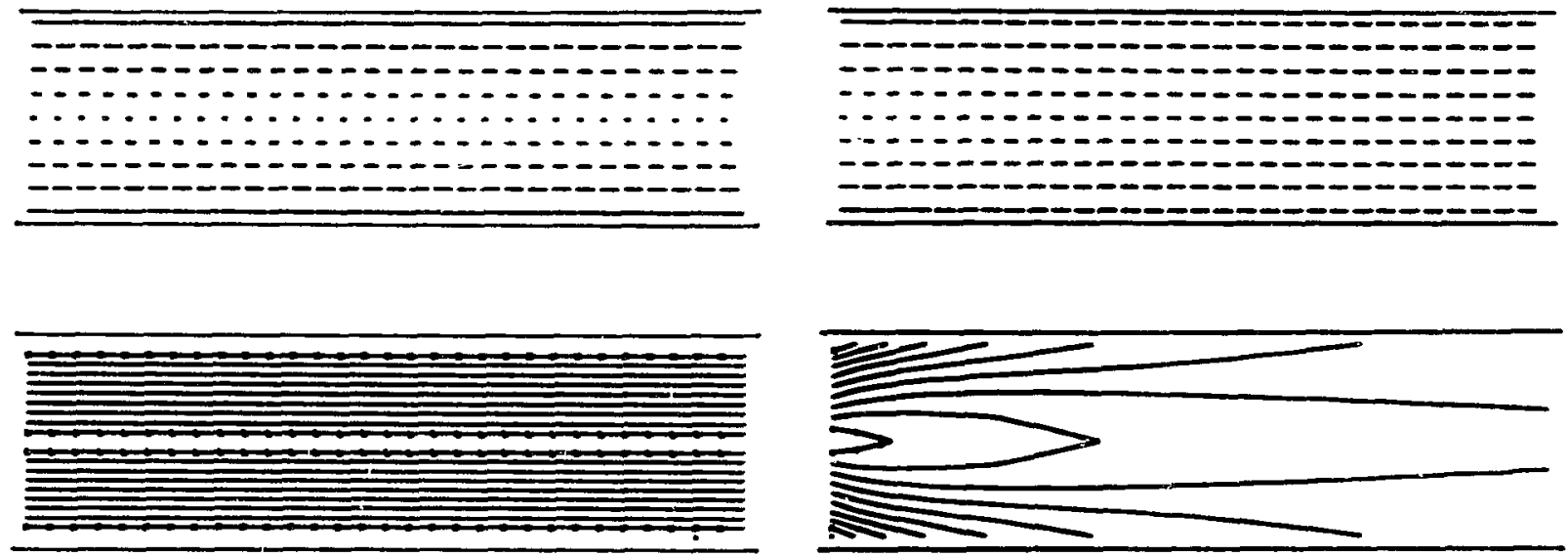

A 9.16, L $=2.79$, Interval $=0.80$

Contours of Mach Number $M$

(3a)

\section{$H=9.22, L=2.80, \quad$ Interval $=0.80$ Contours of Mach Number $M$}

(3b)

Figure 3. Comparison of results obtalned by the TEC method (a) with results obtained by an artificial viscosity method (b). The figure shows the velocity fields with the vector lengths proportional to the speed (upper) and contours of Mach number, $M$, (lower). The maximum contour lines are labeled with an $H$ and the minimum contour lines with an $L$.

The stabllization of the equations in this example fad in the one following, was accomplished with $\xi=1.0$. This choice for $\xi$ has proven satisfactory In a wide variety of applications and does not lead to excessive enhancement of the dispersion errors since $A$ and $B$ are always $\geqslant 0$.

The velocity field and Mach number distribution in $\mathrm{Fig}$. 3a correspond everywhere to the inflow conditlons to within less than $0.2 \%$ and less than $0.4 \%$ respectively. In FIg. $3 b$ the velocity fleld is accelerated along the centerline and decelerated near the boundarles as a coniequence of the viscosity acting in the transverse direction. Since the diffusional sruncation errors in the $y$-direction are very small compared to those in the $x$-direction, the use of $\mu$ to diffuse $u$ in the y-direction results in very excessive diffusion.

For a more comprehensive 1llustration of the method, we consider a-flow problem associated with continuous flow chemical lasers. The intent here is to show the enhanced detail that can be achieved and st11l retain a stable solution. As in the previous example, this problem is also solved by an artifictal viscosity method for comparison.
The flow configuration is shown schematically 1n Fig. 4. The lower fluorine nozzle admits $F$, He, and DF Into the lasing cavity at Mach 3.5 while the upper hydrogen nozzle admits $\mathrm{H}_{2}$ and he at Mach 3.7.

The hydrogen and fluorine mix and react exothermally to produce viorationally exciteó HF molacules, wisich serve as the lasing medium. The calculation begins at the nozzle exit plane and extends downstream. The upper and lower boundaries of the computing region are symetry boundarles. The right boundary is a continuous out $f$ low boundary.

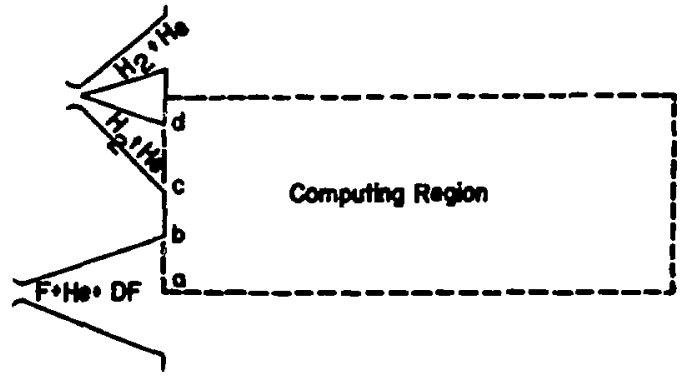

Figure 4. Fluorine ano hydrogen nozzle configuration and computing region. 
The distributions of velocity, density, and specific internal energy at the exit plane of the fluorine and hydrogen nozzles are shown in Fig. 5.
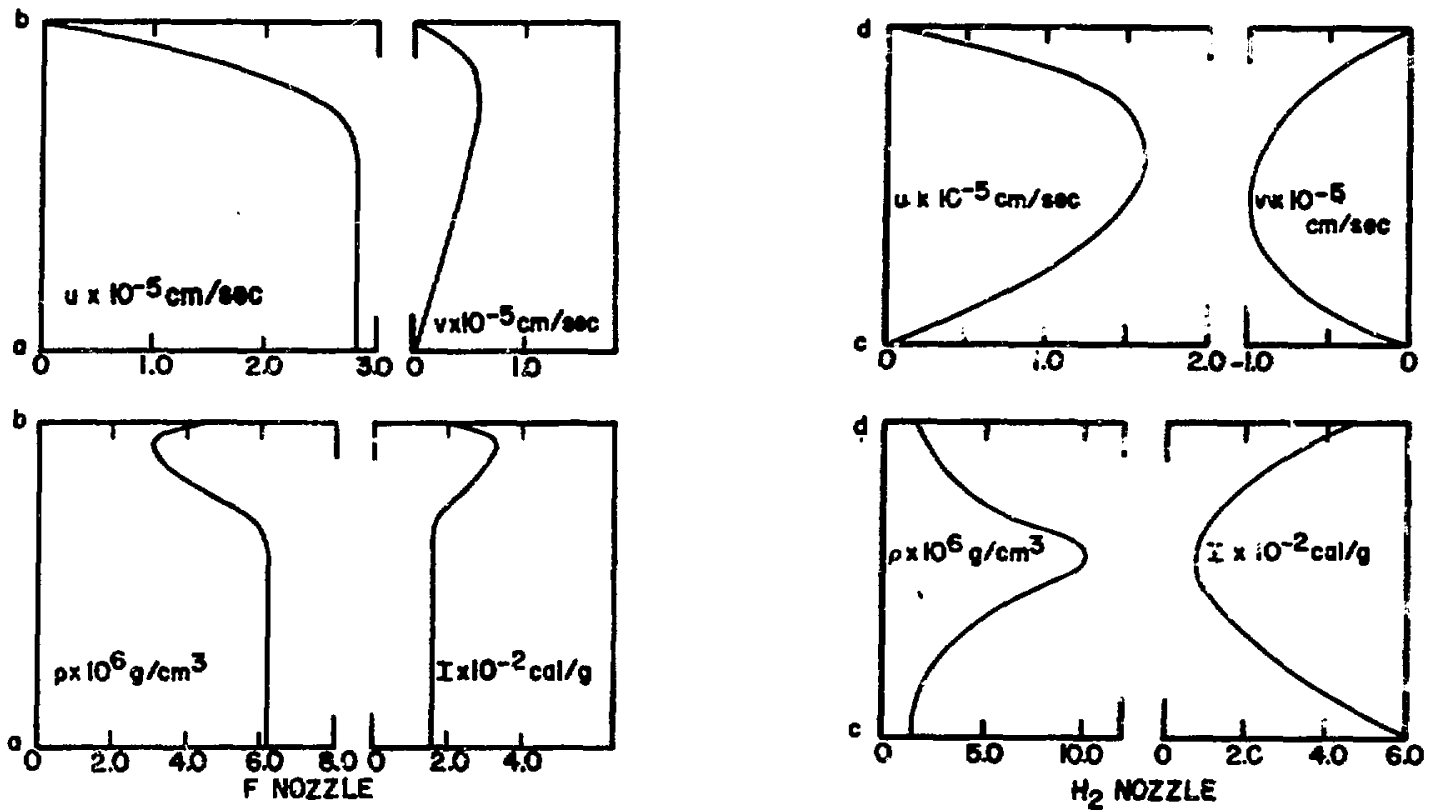

Figure 5. Boundary layer profiles at the exit piane of the fluorine and hydrogen nozzles.

The coordinates (a) and (b) refer to the centerline and wall of the fluorine nozzle while the coordinates (c) and (d) refer to the wall and splitter boundary for the hydrogen nozzle. These exit plane distributions furnish the input values for the calculations when scaled by $\rho_{0}=10^{-5} \mathrm{~g} / \mathrm{cm}^{3}$, $u_{0}=10^{5} \mathrm{~cm} / \mathrm{sec}$, and $I_{0}=239 \mathrm{cal} / \mathrm{g}$. The computational mesh consists of 29 columns and 30 rows of cells with $\delta x=.075$ and $\delta y=.0331$. The time steps for the two calculations are $\delta_{t}=.004$ and $\delta t=.002$. The smaller time otep is used in the artificial viscosity calculation to reduce the amount of viscosity necessary for stability.
For the artificial viscosity calculation, the mixture continuity and species transport equations are stabllized by canceling their low order, diffusional truncation errors. The momentum and energy equations, which include the full viscous stress tensor, are stabilized through the viscosity and thermal conductivity. For this purpose we set $\mu / \rho=\lambda / \rho=.01$ and $k=3 \mu / \rho$. These values are essentially the minima necessary for stability.

The steady state solutions are shown in Fig. 6 . The results obtrined with the TEC method are shown In FIg. 6a for zero physical viocosity and thermal conductivity. The results obtained with artificlal viscosity are shown in Fig. $6 \mathrm{~b}$. 

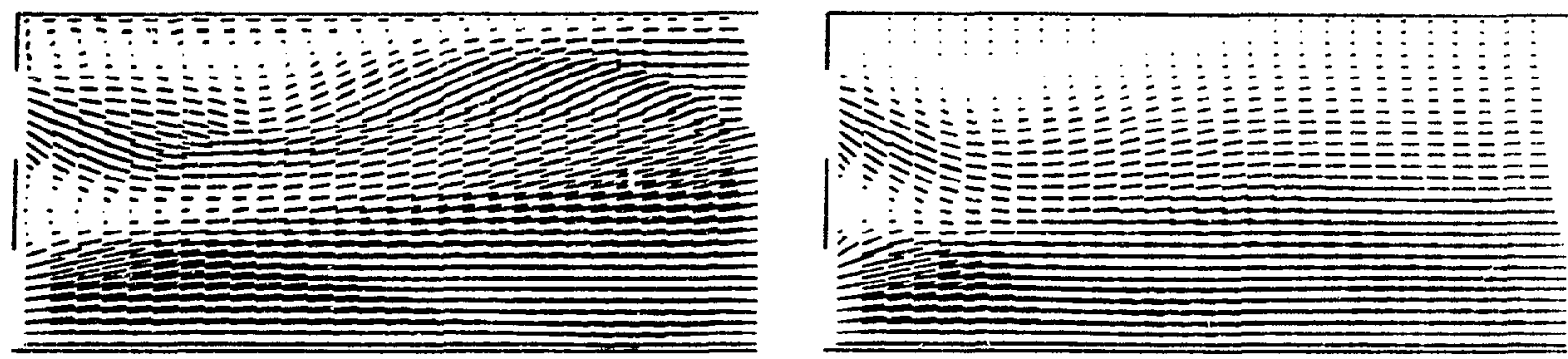

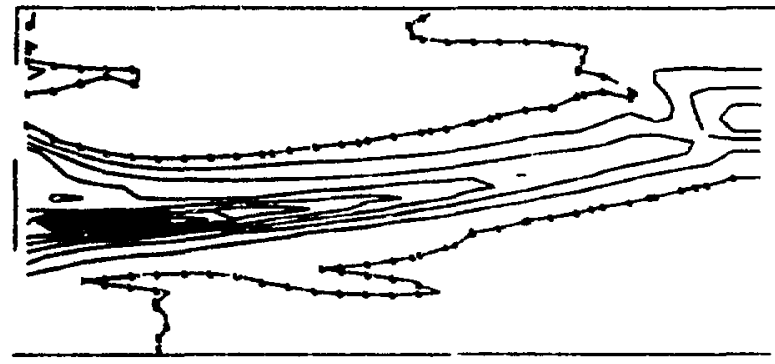

$\mathrm{H}=2.72, \quad \mathrm{~L}=0.53, \quad$ Interval $=0.27$ Contcurs of $I / I_{0}$

(6a)

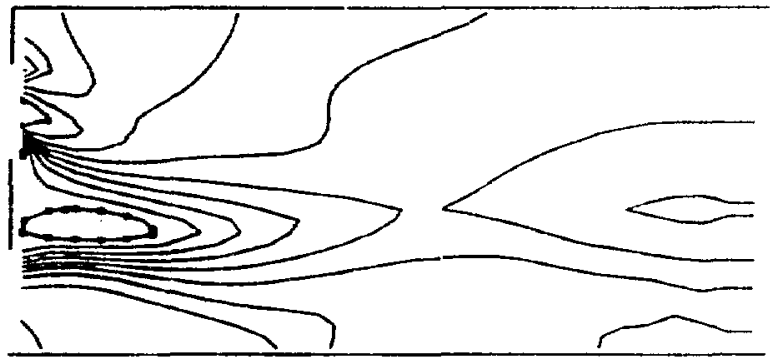

$\mathrm{H}=1.69, \mathrm{~L}=0.48$, Interval $=0.15$ Contours of $I / I_{0}$

(6b)

Figure 6. Comparison of results obtained by the TEC method (a) with results obtalned by an artificial viscosity method (b). The figure shows the velocity flelds with the yector lengths proportional to the speed (upper) and contours of specific internal energy, $I$, (lower). The maximum contour lines are labeled with an $H$ and the mirtmum contour lines with an $\mathrm{L}$.

The figure shows the velocity flelds with the vector lengths proportional to the speed, and contours of specific incernal energy. The raxfmum contour lines are designated with an $(H)$ and the minimum contour IInes with an (L). The values of $\mathrm{H}, \mathrm{L}$, and the Interval between contour lines are given below each contour plot.

The velocity flelds obtained in the two calculations are much different. The inflow velocity profiles are rapidly smoothed in (b) but retained in (a). This is because the transverse gradients, In particular $\partial u / \partial y$, are smoothed by the large diffusion coefficient, $\mu$, in (b) as compared to the small diffusion coeffictent, $B=-(1 \pm 5)\left(0 v^{2} \delta t / 2\right.$ $\left.+(\partial \rho v / \partial y) \delta y^{2} / 4\right\}$, in (a). The much higher flow speeds in (a) result from the lack of kinetic energy dissipation by the artificlal viscosity. In (a), a twin vortex can be seen in the wake region separating the fluorine and hydrogen nozzles. The vortex residing in the upper left corner for both calculations has been enhanced in (a). A shock has appeared in the upper right corner in (a), as a result of the collision of the hydrogen stream with the upper symmetry boundary.

The contours of specific internal energy are considerably different. The maximum values of $I / I_{0}$ reside in the wake region between the hydrogen and fluorine nozzles for both calculations. The maximum value in (a) is greater than in (b) due to the enhanced mixing of reactants by the twin vottex and consequent heat release fron the chemical reaction. The steeper gradients in (a) reflect the absence of thermal conductivity. Downstream in (a), the high values of $I / I_{0}$ reside in the region where the 
exotherutc chemical reaction is occurring. This structuze of the reaction zone is lost in (b) due to the viscous dissipation. This is clearly shom In $E I_{8} \cdot 7$.

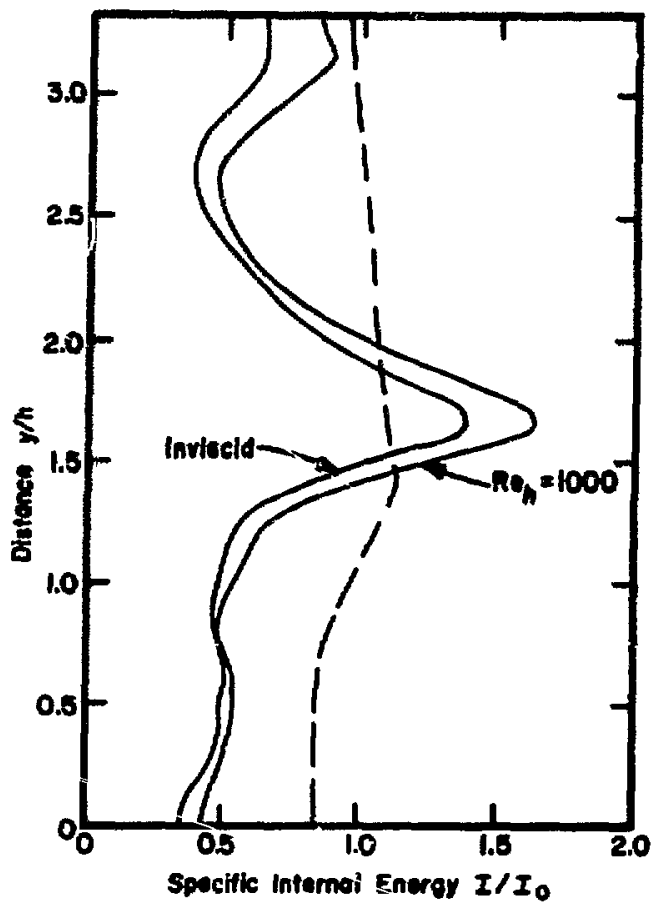

Figure 7. Distributions of specific internal energy at $x=4.7 \mathrm{~h}$ downstream of the nozzle extt platis. The dashed curve is a result of the artificial viscostcy calculation. The two solid curves are results obtained by the TRC method. The curve labeled Inviacid ccrresponds to the results presented in F1g, 6a for zero physical viscosity and thermal conductivity. The curve labeled $\mathrm{Re}_{\mathrm{h}}=1000$ shows the sensitivity of I to the physical viscosity.

Figure 7 shows distributions of specific internal energy at $x=4$.7h downstream of the nozzle exit plane. The length scale $h$ is the half-width of the fluorine nozzle.

The dashed curve is a result of the artificial viscosity calculation. The two solid curves are results obtained with the TEC method. The curve labeled Inviscid corresponds to the results presented in $\mathrm{Fi}_{\mathrm{B}}$. 6a. The additional curve corresponds to a Reynolds number of 1000 based on the fluorine nozzle half-width and core-flow conditions. This curve shows the sensitivity of the specific incernal energy to the physical viscosity. The eghanced detell in these curves, particularly in the region of chemical reaction, is apparent. This detail to lost in the artificial viscosity calculetfor due to the excessive kinetic energy dissipation.

\section{vII. SUIGARY}

$A$ wethod of general applicabilicy has been described for stabilizing Eulerian Elutd dynamics calarlations. It produces a algnificant increase in accuracy and, In any Instances, allows for a larger compucational time step over methods using an artifictal viscosity scheme to achieve stability. The essence of the wethod is the local cancellation of the diffustonal truncation errors arising from the finite difference equations. The applicability of the method has been demonstraced by applying it in the RICE code, which calculates the transient, twodimensional flows of chemically reaceing wixtures. The effectiveness of the method is demonstrated in the results of two numerical examples.

\section{REFERENCES}

1. R. D. R1chtweyer and K. H. Horton, "Difference Kethods for Initial Value Problems," 2nd editior, Interscience, New York, 1967.

2. C. W. Hirt, J. Comp. Phys. 2, 339 (1968).

3. O. A. Farwer, T. D. Butler, H. C. Rivard, Los Alamos Sclentific Laboratory Report (To be published).

4. F. H. Harlow and A. A. Amsden, J. Comp. Phys. $\underline{8}$, 197 (1971). 


\section{APEEKDIX A}

\section{DERIVATION OF THE TEC METHOD}

A more comprehensive derivation of the method is given here to show spectifically the implications of the sisple derivation presented in Sec. II, We begin with Eq. (2.2) which is

$$
D E(\rho)=F D(\rho)+E \frac{\partial^{2} \rho}{\partial x^{2}}+o \cdot t \cdot e
$$

The stabllity of $F D(\rho)=1$ depends upon the algebraic sign of $\varepsilon$. To insure a prsicive diffusion coefficlent which is necessary for stability, we introiuce into Eq. $(A-1)$ the diffusive term

$$
\operatorname{FD}\left(A \frac{\partial^{2} \rho}{\partial x^{2}}\right)=A \frac{\partial^{2} \rho}{\partial x^{2}}+\varepsilon_{1} \frac{\partial^{2} \rho}{\partial x^{2}}+0 . t . e ., \quad(A-2)
$$

where $\operatorname{FD}\left(A a^{2} \rho / \partial x^{2}\right)$ is the finite difference aproximation of $A \partial^{2} p / \partial x^{2}$, $A$ is a diffusion coeffictent to be defined lacer, and the truncation errors are denoted by $\varepsilon_{1} \partial^{2} p / \partial x^{2}$ for the diffusive errors and o.t.e. for the others. The value of $\varepsilon_{1}$ depends upon the form of the finite difference approximation of $A \partial^{2} \rho / \partial x^{2}$. For FD $\left(A \partial^{2} \rho / \partial x^{2}\right)=A_{i}\left(\rho_{i+1}-2 \rho_{1}+\rho_{1-1}\right)$ $/ \delta x^{2} \varepsilon_{1}$ would be zero; whereas for $\operatorname{FD}\left(A \partial^{2} \rho / \partial x^{2}\right)$ $=\frac{1}{2}\left(A_{i+\frac{1}{2}}+A_{1-\frac{1}{2}}\right)\left(p_{i+1}-2 p_{1}+p_{i-1}\right) / x \delta, \varepsilon_{1}$ would be equal to $\left(\partial^{2} A / \partial x^{2}\right) \delta x^{2} / 8+h$ gher order terms. Incluston of Eq. (A-2) in Eq. (A-1) yields

$$
\begin{aligned}
\operatorname{DE}(\rho)= & \operatorname{FD}(\rho)-\operatorname{FD}\left(A \partial^{2} \rho / \partial x^{2}\right)+\left(A+\varepsilon+\varepsilon_{1}\right) \\
& \partial^{2} \rho / \partial x^{2}+\text { o.t.e. }
\end{aligned}
$$

The coefficient $A$ is chosen such that $A+\varepsilon+\varepsilon_{1}>0$ in accord with Hirt's theory bince we solve

$$
F D(\rho)=F D\left(A \partial^{2} \rho / \partial x^{2}\right)
$$

In place of $F D(p)=0$. Negative values of $\left(\epsilon+\varepsilon_{1}\right)$, which are a source of Instability, are countered with a positive vaiue of $A$. Positive values of $\left(\varepsilon+\varepsilon_{1}\right)$ are stablitizing and are reduced by inclusion of a negative value of $A$.

Equation (A-4) is a non-conservative differeace equation. It can be replaced with a conservative equation $a 3$ follows. Equation $(A-3)$ is written as

$$
\begin{aligned}
D E(D)=E D(D)= & E D\left\{\partial\left[\left(A+A^{\prime}\right) \partial p / \partial x\right\} / \partial x\right\} \\
+ & \operatorname{ED}\left[(\partial A / \partial x)(\partial p / \partial x)+\partial\left(A^{\prime} \partial D / \partial x\right) /\right. \\
& \partial x\}+\left(A+E+\varepsilon_{1}\right) \partial^{2} p / \partial x^{2} \\
+ & \text { o.t.e., }
\end{aligned}
$$

by adding and subtracting $F D((\partial A / \partial x)(\partial \rho / \partial x)+$ $\left.\partial\left(A^{\prime} 3 p / \partial x\right) / \lambda x\right]$ where $A^{\prime}$ is deternined such that

$$
\operatorname{FD}\left[(\partial A / \partial x)_{j}(\partial p / \partial x)+\partial\left(A^{\prime} \partial p / \partial x\right) / \partial x\right]=0 . t \cdot e .
$$

We can write Eq. (A-6) as a differential equation

$$
\begin{aligned}
(\partial A / \partial x)_{j}(\partial \rho / \partial x) & +\partial\left(A^{\prime} \partial \rho / \partial x\right) / \partial x \\
& +\left(\varepsilon_{2}+\varepsilon_{3}\right) \partial^{2} \rho / \partial x^{2}=0 .
\end{aligned}
$$

by noting that

$$
\begin{aligned}
\operatorname{FD}[(\partial A / \partial x)(\partial \rho / \partial x)] & =(\partial A / \partial x)(\partial \rho / \partial x)+E_{2} \partial^{2} \rho / \partial x^{2} \\
& + \text { o.t.e. }
\end{aligned}
$$

and

$\operatorname{FD}\left[\partial\left(A^{\prime} \partial p / \partial x\right) / \partial x\right]=\partial\left(A^{\prime} \partial \rho / \partial x\right) / \partial x+\varepsilon_{3} \partial^{2} \rho / \partial x^{2}$

$$
\text { to.t.e. }
$$

where $\epsilon_{2}$ and $\epsilon_{3}$ are the coefficients of diffusion arising from truncation errors. These coefficients generally involve derivatives of $A$ and $A^{\prime}$ so that Eq. $(A-7)$ cannot be easily integrated.

We obtain the results given in Sec. II. by neglecting $\varepsilon_{1}, \varepsilon_{2}$, and $\varepsilon_{3}$ In comparison to $\varepsilon_{\text {. These }}$ diffusion coefficients are higher order than $E$ when $A$ and its derivatives are the order of $\epsilon$. Neglect of $\varepsilon_{1}$, which generally involves derivatives of $A$ times, say $\delta t$ or $\delta x^{2}$, results in an algebralc equation for $A, 1, e ., A+E>0$. Neglect of $\varepsilon_{2}$ and $E_{3}$ reduces $E q$. $(A-7)$ to Eq. (2.11) with solution for $A^{\prime}$ given by Eq. (2.13). 
TRLNCATION ERRORS FOR THE RICE FLOH EQUATIONS

In this append1x a casplece lise of the zow order truncation errors is glven for the RICE flow equations neglecting the molccular transport terms. The RICE finte-difference equations are given in Sec. IITA and are not repeaced here. The low order truncation errors including the diffusional ezrors are as follows.

\section{Mass Equation}

$$
\begin{aligned}
& \frac{\partial \rho}{\partial t}+\frac{\partial \rho u}{\partial x}+\frac{\partial \rho v}{\partial y}=F D(\rho)+(2 \theta-1) \frac{\delta t}{2} ;\left(u^{2}+c^{2}\right) \\
& \frac{\partial^{2} \rho}{\partial x^{2}}+\left(v^{2}+c^{2}\right) \frac{\partial^{2} p}{\partial y^{2}}+4 u \frac{\partial \rho}{\partial x} \frac{\partial u}{\partial x}+2 p \frac{\partial}{\partial x}\left(u \frac{\partial u}{\partial x}\right) \\
& +\frac{\partial \rho}{\partial x} \frac{\partial c^{2}}{\partial x}+2 \frac{\partial^{2} \rho v v}{\partial x \partial y}+4 v \frac{\partial g}{\partial y} \frac{\partial v}{\partial y}+2 p \frac{\partial}{\partial y}\left(v \frac{\partial v}{\partial y}\right) \\
& +\frac{\partial p}{\partial y} \frac{\partial c^{2}}{\partial y}:-\frac{\partial x^{2}}{2 !}: 6 \frac{\partial u}{\partial x} \frac{\partial^{2} c}{\partial x^{2}}+4 u \frac{\partial^{3} \partial}{\partial x^{3}}+3 \frac{\partial \rho}{\partial x} \\
& \frac{\partial^{2} u}{\partial x^{2}}+\rho \frac{\partial^{3} u}{\partial x^{3}} !-\frac{5 y^{2}}{24} ! 6 \frac{\partial v}{\partial y} \frac{\partial^{2} p}{\partial y^{2}}+4 v \frac{\partial^{3} \rho}{\partial y^{3}} \\
& +3 \frac{\partial \rho}{\partial y} \frac{\partial^{2} v}{\partial y^{2}}+\rho \frac{\partial^{3} v}{\partial y^{3}} \mid+ \text { o.t.e. }
\end{aligned}
$$

where $\mathrm{FD}(\rho)$ is given by $\mathrm{Eq} .(3.1)$.

2. Momentum Zquat1oลs

For the $x$-component, we have

$$
\begin{aligned}
\frac{\partial \rho u}{\partial t} & +\frac{\partial \rho u^{2}}{\partial x}+\frac{\partial p u v}{\partial y}+\frac{\partial p}{\partial x}-\frac{\partial \sigma_{x x}}{\partial x}-\frac{\partial \sigma x y}{\partial y}=F D(\rho u) \\
& +\frac{\delta t}{2}\left\{\rho\left((2 \phi-1) c^{2}-3 u^{2}\right) \frac{\partial^{2} u}{\partial x^{2}}-\rho v^{2} \frac{\partial^{2} u}{\partial y^{2}}\right. \\
& +c^{2}\left(2 \frac{\partial \rho}{\partial x} \frac{\partial u}{\partial x}+u \frac{\partial^{2} \rho}{\partial x^{2}}+\frac{\partial^{2} \rho v}{\partial x^{2} y}\right)+2 \frac{\partial c^{2}}{\partial x}\left(\frac{\partial \rho u}{\partial x}\right. \\
& \left.+\frac{\partial \rho v}{\partial y}\right)-3 \frac{\partial u^{2}}{\partial x} \frac{\partial \rho u}{\partial x}-u^{3} \frac{\partial^{2} \rho}{\partial x^{2}}-2 \frac{\partial}{\partial x}\left(\frac{\partial \rho u^{2} v}{\partial y}\right. \\
& \left.+u \frac{\partial p}{\partial x}\right)-\frac{\partial}{\partial y}\left(v \frac{\partial p}{\partial x}+u \frac{\partial p}{\partial y}\right)-2 \frac{\partial u}{\partial y} \frac{\partial \rho v^{2}}{\partial y} \\
& \left.-u \frac{\partial^{2} p v^{2}}{\partial y^{2}}\right\}-\frac{\delta x^{2}}{24}\left(12 \frac{\partial \rho u}{\partial x} \frac{\partial^{2} u}{\partial x^{2}}+8 \rho u \frac{\partial^{3} u}{\partial x^{3}}\right.
\end{aligned}
$$

$$
\begin{aligned}
& +12 \frac{\partial u^{2}}{\partial x} \frac{\partial^{2} p}{\partial x^{2}}+u^{2} \frac{\partial^{3} p}{\partial x^{3}}+24 \frac{\partial \rho}{\partial x}\left(\frac{\partial u}{\partial x}\right)^{2} \\
& \left.+3 \frac{\partial}{\partial y}\left(u v \frac{\partial^{2} p}{\partial x^{2}}+\rho u \frac{\partial^{2} v}{\partial x^{2}}\right)+\frac{\partial^{3} p}{\partial x^{3}}\right) \\
& -\frac{\delta y^{2}}{2 u} \mid 6 \frac{\partial \rho v}{\partial y} \frac{\partial^{2} u}{\partial y^{2}}+4 \rho v \frac{\partial^{3} u}{\partial y^{3}}+6 \frac{\partial u v}{\partial y} \frac{\partial^{2} \rho}{\partial y^{2}} \\
& \left.+4 u v \frac{\partial^{3} \rho}{\partial y^{3}}+6 \frac{\partial v}{\partial y} \frac{\partial \rho}{\partial y} \frac{\partial u}{\partial y}+3 \frac{\partial \rho u}{\partial y} \frac{\partial^{2} v}{\partial y^{2}}+\rho u \frac{\partial^{3} v}{\partial y^{3}}\right] \\
& + \text { o.t.e. }
\end{aligned}
$$

where $E D(\rho u)$ is given by $8 q$. (3.4.).

For the $y$-component, the approprlate equation is obtained by substituting $v$ and $y$ for $u$ and $x$ respectIvely in $\mathrm{Eq} .(\mathrm{B}-2)$.

\section{Specific Internal Energy Equation}

$$
\begin{aligned}
& \frac{\partial c I}{\partial t}+\frac{\partial \rho u I}{\partial x}+\frac{\partial \rho V I}{\partial y}+\left(p-\sigma_{y x}\right) \frac{\partial u}{\partial x}+\left(p-\sigma_{y y}\right) \frac{\partial v}{\partial y}+\sigma_{x y}( \\
& \left.\frac{\partial u}{\partial y}+\frac{\partial v}{\partial x}\right)-\frac{\partial}{\partial x}\left(k \frac{\partial I}{\partial x}\right)-\frac{\partial}{\partial y}\left(k \frac{\partial I}{\partial y}\right)=F D(\rho I)+\frac{\delta t}{2}\left\{-\rho u^{2} \frac{\partial^{2} I}{\partial x^{2}}\right. \\
& -\rho v^{2} \frac{\partial^{2} I}{\partial y^{2}}-u\left\{2 \frac{\partial I}{\partial x} \frac{\partial \rho u}{\partial x}+I \frac{\partial^{2} \rho u}{\partial x^{2}}\left|+\frac{u \partial}{\partial x}\right| \frac{\partial \rho v I}{\partial y}\right. \\
& +p\left(\frac{\partial u}{\partial x}+\frac{\partial v}{\partial y}\right) \mid-v\left[2 \frac{\partial I}{\partial y} \frac{\hat{\rho} \rho v}{\partial y}+I \frac{\partial^{2} \rho v}{\partial y^{2}}\right\rfloor \\
& +\frac{v \partial}{\partial y}\left[\frac{\partial p u I}{\partial x}+P\left(\frac{\partial u}{\partial x}+\frac{\partial v}{\partial y}\right)\right]+\frac{\partial}{\partial t} \mid \gamma p I\left(\frac{\partial u}{\partial x}\right. \\
& \left.+\frac{\partial v}{\partial y}\right)-2 c^{2} \frac{\partial \rho}{\partial t} \frac{\partial u}{\partial x}-\frac{\partial \rho I}{\partial x} \frac{\partial u}{\partial t}-\frac{\partial \rho I}{\partial y} \frac{\partial v}{\partial t} \\
& \left.-2 \gamma \rho I \frac{\partial}{\partial t}\left(\frac{\partial u}{\partial x}+\frac{\partial v}{\partial y}\right)\right\}-\frac{\delta x^{2}}{24}\left\{\left(6 \rho \frac{\partial u}{\partial x}+12 u \frac{\partial \rho}{\partial x}\right)\right. \\
& \frac{\partial^{2} I}{\partial x^{2}}+4 \rho u \frac{\partial^{3} I}{\partial x^{3}}+3 \frac{\partial \rho I}{\partial x} \frac{\partial^{2} u}{\partial x^{2}}+\gamma \rho I \frac{\partial^{3} u}{\partial x^{3}} \\
& +\left(12 u \frac{\partial I}{\partial x}+6 I \frac{\partial u}{\partial x}\right) \frac{\partial^{2} \rho}{\partial x^{2}}+4 u I \frac{\partial^{3} \rho}{\partial x^{3}}+I 2 \frac{\partial u}{\partial x} \\
& \left.\frac{\partial \rho}{\partial x} \frac{\partial I}{\partial x}\right\}-\frac{\delta y^{2}}{24}\left\{\left(6 \rho \frac{\partial v}{\partial y}+12 v \frac{\partial \rho}{\partial y}\right) \frac{\partial^{2} I}{\partial y^{2}}\right. \\
& +4 \rho v \frac{\partial^{3} I}{\partial y^{3}}+3 \frac{\partial \rho I}{\partial y} \frac{\partial^{2} v}{\partial y^{2}}+\gamma \rho I \frac{\partial^{3} v}{\partial y^{3}}+\left(12 v \frac{\partial I}{\partial y}\right.
\end{aligned}
$$


$\left.\left.+6 I \frac{\partial v}{\partial y}\right) \frac{\partial^{2} \rho}{\partial y^{2}}+4 v I \frac{\partial^{3} \rho}{\partial y^{3}}+12 \frac{\partial v}{\partial y} \frac{\partial \rho}{\partial y} \frac{\partial I}{\partial y}\right\}$

+ h.o.t.

$(\mathrm{B}-3)$

where $F(p I)$ is given by $\mathrm{Eq} .(3.10)$.

\section{Spectes Transport Equations}

For spectes $a$, we have

$$
\begin{aligned}
\frac{\partial \rho_{\alpha}}{\partial t} & +\frac{\partial u \rho_{\alpha}}{\partial x}+\frac{\partial v \rho_{\alpha}}{\partial y}=F D\left(\rho_{\alpha}\right)+\frac{\delta t}{2} \int \frac{\partial u}{\partial x} \frac{\partial \rho_{a}}{\partial t} \\
& -\rho_{\alpha} u \frac{\partial^{2} u}{\partial x^{2}}+\rho_{\alpha} \frac{\partial^{2} u}{\partial x \partial t}+\frac{\partial u}{\partial t} \frac{\partial \rho_{\alpha}}{\partial x}+u \frac{\partial u}{\partial x} \frac{\partial p_{a}}{\partial x}
\end{aligned}
$$

$$
\begin{aligned}
& -u \frac{\partial^{2} \rho_{\alpha}^{v}}{\partial x \partial y}+\frac{\partial v}{\partial y} \frac{\partial \rho_{\alpha}}{\partial t}-\rho_{a} v \frac{\partial^{2} v}{\partial y^{2}}+\rho_{a} \frac{\partial^{2} v}{\partial y \partial t} \\
& \left.+\frac{\partial v}{\partial t} \frac{\partial \rho_{\alpha}}{\partial y}+v \frac{\partial v}{\partial y} \frac{\partial \rho_{a}}{\partial y}-v \frac{\partial^{2} \rho_{\alpha}^{u}}{\partial x \partial y}\right)-\frac{\delta x^{2}}{24}
\end{aligned}
$$$$
\left[6 \frac{\partial u}{\partial x} \frac{\partial^{2} \rho_{a}}{\partial x^{2}}+4 u \frac{\partial^{3} \rho_{a}}{\partial x^{3}}+3 \frac{\partial \rho_{\alpha}}{\partial x} \frac{\partial^{2} u}{\partial x^{2}}+\rho_{a} \frac{\partial^{3} u}{\partial x^{3}}\right]
$$$$
-\frac{\delta y^{2}}{24} \mid 6 \frac{\partial y}{\partial y} \frac{\partial^{2} \rho a}{\partial y^{2}}+4 v \frac{\partial^{3} \rho \alpha}{\partial y^{3}}+3 \frac{\partial \rho}{\partial y} \frac{\partial^{2} y}{\partial y^{2}}
$$$$
\left.+p_{a} \frac{\partial^{3} y}{\partial y^{3}}\right]+ \text { h.o.t. . }
$$

where $E D\left(\rho_{a}\right)$ 1s given by Eq. (3.12). 